\title{
A CONCEPÇÃO DE PAIDEIA COMO REFERENCIAL PARA A POLÍTICA JURÍDICA
}

Resumo:

*Josemar Sidinei Soares

A política jurídica é o estudo do que deveria ser o direito, diferente da ciência jurídica, que estuda o que é o direito. A política jurídica tem a responsabilidade de dar diretrizes para o aprimoramento do direito enquanto instrumento de organização social. Para isto a política jurídica precisa ampliar seu entendimento acerca do ser humano. A paideia grega surge como referencial de valor para o desenvolvimento de uma política jurídica mais humanista e funcional à sociedade. $\mathrm{O}$ problema de pesquisa é: pode a Paideia ser referencial para a Política Jurídica? O método a ser utilizado é o dedutivo.

Palavras-chave: Política Jurídica; Paideia; Humanismo; Educação; Direito

\section{THE CONCEPTION OF PAIDEIA AS A FRAMEWORK FOR LEGAL POLICY}

Abstract:

Legal policy is or study of what should be or law, different from legal science, which studies or what is or law. A legal policy with the responsibility to direct or open the way for the organization of social networks. For this, the legal policy precisely expands its understanding of the human being. Greek Paideia appears as a valuable reference for the development of a more humanist and functional legal policy for society. Or the research problem is: could Paideia be a reference for Legal Policy? The method to be used is the deductive.

Keywords: Legal Policy; Paideia; Humanism; Education; Law

\section{INTRODUÇÃO}

Um dos maiores desafios para o direito continua sendo não tanto a atividade da ciência jurídica, mas aquela da política jurídica, que é o estudo do direito que deveria ser, enquanto a primeira se dedica a entender o direito que é, o direito posto.

Isto porque para instrumentalizar adequadamente a política jurídica não é suficiente o conhecimento jurídico, mas requerem-se aprofundamentos acerca da integralidade da realidade humana.

Para tanto é necessário o estudo não apenas das regras jurídicas, mas conhecer as diversas esferas de atuação humana, como a política, a econômica, a estética, a espiritual, a lúdica, entre outras. Para se aprimorar a sociedade é indispensável antes entender os

\footnotetext{
* Doutor em Filosofia pela Universidade Federal do Rio Grande do Sul. Mestre em Educação pela UFSM. Mestre em Ciência Jurídica pela UNIVALI. Professor no Programa de Pós-Graduação Stricto Sensu em Ciência Jurídica - UNIVALI, Itajaí, Santa Catarina, Brasil. E-mail: jsoares@univali.br CONPEDI LAW REVIEW | EVENTO VIRTUAL | v. 6 | n. 1 | p. 236 - 251 | JAN - DEZ | 2020 
indivíduos que compõem a sociedade e como estes podem se desenvolver enquanto pessoas e membros de um corpo social.

Portanto, a política jurídica não pode ser desconectada de sua dimensão pedagógica, pois dizer como o direito deveria ser significa partir do pressuposto que o jurista é capaz de orientar a sociedade a encontrar um caminho mais funcional para si. É uma tarefa de grande responsabilidade, e que exige do jurista uma formação humanista mais ampla.

Neste sentido, entende-se que a retomada do estudo de alguns fenômenos culturais específicos pode auxiliar o operador do direito a tornar-se mais capaz na instrumentalização da política jurídica. Entre estes estudos está o da paideia grega.

Paideia é o termo que Werner Jaeger utiliza para expressar o processo de formação espiritual e histórico do homem grego, demonstrando que em cada estágio se buscou encontrar os elementos capazes de cultivar e refinar a existência humana. Propor paideia significa procurar condições que tornem a realidade humana mais adequada à sua natureza, enquanto indivíduo e sociedade. Seja na poesia, seja política, no direito, ou mesmo na filosofia, por trás das manifestações culturais gregas se encontrava sempre a busca por aprimorar o ser humano. As atividades culturais não eram fins em si mesmas, mas meios para a paideia, a pedagogia comunitária e humanista.

Com este artigo busca-se apresentar a proposta da paideia como um referencial de valor para o aprimoramento dos estudos e operações envolvendo a política jurídica. Por isto, na primeira parte se apresenta a ideia de cultura vinculada à filosofia, para então em segundo momento ser introduzida a proposta da paideia. Na parte final adentra-se o argumento da política jurídica. As considerações finais encerram o trabalho relacionando paideia e política jurídica.

Portanto, o problema de pesquisa é: pode a Paideia ser utilizada como referencial para a Política Jurídica?

O artigo utiliza o método dedutivo, por meio de pesquisa bibliográfica.

\section{FILOSOFIA E CULTURA}


A filosofia, desde suas origens pré-socráticas, revela-se um instrumento capaz de colocar qualquer objeto sob análise crítica. A filosofia, na medida em que exercita o conhecimento de como pensar, permite justificar ou criticar qualquer objeto, colocar em exame qualquer pensamento. $^{2}$

Do ponto de vista histórico a filosofia pode ser entendida como produto da cultura grega. A filosofia nasce na Grécia, como resultado de séculos de desenvolvimento intelectual com as poesias épicas, com as tragédias e comédias, com toda uma tradição que busca desvelar o real, até o surgimento de Tales de Mileto e dos demais pensadores ditos présocráticos, pesquisadores da cosmologia. A filosofia, nesse sentido, é produto da cultura, da cultura grega.

Mas a filosofia, no momento em que nasce, consegue se libertar da cultura que a gerou, torna-se um instrumento livre, capaz de examinar e criticar até mesmo a cultura que lhe deu causa. Sendo assim, já em seu período incipiente identifica-se Xenofonte dizendo que se os animais cultuassem deuses o fariam criando as divindades com patas e chifres, às suas imagens. Depois Sócrates seria condenado também por criticar os deuses da tradição de seu povo. Ou seja, a cultura que gera a Filosofia não está livre de ser examinada e criticada pela Filosofia.

Desse modo é possível visualizar como a relação entre Cultura e Filosofia é intrincada. De um lado toda corrente filosófica, todo pensamento filosófico, é fruto de uma época, de uma cultura, de uma dada sociedade histórica. Assim, a filosofia grega nasce da cultura grega, a medieval da sociedade medieval, as correntes modernas dos modos econômicos e sociais de organização dos Estados modernos. Mas mesmo isto não impediu filósofos gregos de criticarem a cultura grega, de filósofos medievais colocarem em exame a tradição medieval, e assim por diante.

Portanto, a Filosofia tem a capacidade de mediar o exame crítico de qualquer realidade cultural, incluindo aquela que lhe gera. Com o surgimento da racionalidade científica moderna a Filosofia potencializa esta capacidade, pois passa a dispor de outros instrumentos técnicos (provenientes da metodologia científica) para analisar e criticar a realidade cultural.

\footnotetext{
${ }^{2}$ Para uma exposição desta capacidade da filosofia examinar criticamente os elementos culturais dados na história humana ver Soares (2019). 
Avançando na abordagem o filósofo e o cientista se deparam com a constatação de que a cultura é plural, de que existe uma imensa pluralidade e diversidade de culturas ao redor do planeta e no tempo. Do ponto de vista empírico é inviável falar em modelo de cultura ideal, diante da evidência da profunda diversidade que toca a realidade humana.

Trata-se, na verdade, de uma pluralidade não só quantitativa no espaço e no tempo históricos, mas qualitativamente interior a cada paradigma cultural, que apresenta sempre uma estrutura em processo incessante de autodiferenciação. A cultura mostra aqui sua solidariedade profunda com a vida que também se autodiferencia numa profusão quase infinita de formas e que mostra de maneira poderosamente original esse dinamismo autodiferenciador justamente na vida da cultura. (VAZ, 2002a, p. 89).

Toda cultura é um fenômeno da vida, no sentido de que se manifesta a partir da interação histórica de um dado grupo com as circunstâncias existenciais que o tocam. Sendo assim, diversa é a aparência cultural, porque diversas são as circunstâncias que influenciam o agir humano.

No entanto, se por um lado a evidência empírica atesta a multiplicidade cultural, por outro há algo de unitário que subjaz às diferenças culturais, a unidade que persiste apesar das diversidades empíricas. Desse modo a filosofia retoma a discussão que a instiga desde suas origens, a relação entre o uno e o multíplice. Como identificar o uno que está para além do multíplice fenomênico?

Este estudo é possível porque, de qualquer forma, o fundamento da cultura se encontra sempre em seu criador: "a ontologia da cultura é um desdobramento da ontologia do homem, a antropologia filosófica". (VAZ, 2002a, p. 89). Para Vaz o ser humano se constitui ontologicamente na capacidade de criação cultural, vez que isto o distingue dos demais seres vivos.

Assim, ao criar uma cultura específica, localizada espacialmente e temporalmente, o ser humano permite que aquela obra obtenha transcendência dos limites espaciais e temporais, pois o resultado passará a integrar a ontologia da cultura, o mundo da cultura. Desse modo, a criação cultural grega, com sua filosofia e sua poesia, por exemplo, persiste como criação cultural, ainda que o povo que a tenha gerado já não exista historicamente. ${ }^{3}$

\footnotetext{
3 "O ato da criação cultural deposita a obra da cultura no aqui e agora da existência histórica do homem e no tempo do mundo, e ela passa a existir - com uma existência precária e ameaçada - arrastada no fluxo das CONPEDI LAW REVIEW | EVENTO VIRTUAL | v. 6 | n. 1 | p. 236 - 251 | JAN - DEZ | 2020 
Vaz prossegue no raciocínio:

Qual a natureza da unidade da cultura pensada numa conceptualidade filosófica e que afirmamos subjacente à multiplicidade empírica das culturas? Trata-se de uma unidade analógica justamente porque o ato criador do objeto cultural é expressão da abertura do homem à universalidade do ser e é no horizonte dessa universalidade que a obra de cultura se situa e adquire a sua idealidade simbólica. Devemos dizer, pois, que a unidade da cultura é conceptualmente assegurada pelas categorias de estrutura e relação estabelecidas pela antropologia filosófica e articuladas discursivamente pelo movimento dialético de autoexpressão do sujeito, impelido do princípio da 'ilimitação tética'. A unidade é, pois, uma unidade na diferença (por isso mesmo unidade analógica) que permite ao homem realizar-se na pluralidade das culturas históricas e na rica profusão de formas por elas ostentadas. (VAZ, 2002, p. 90-91).

A cultura, assim, reside na dialética de transcendência do humano como abertura ao horizonte do ser. Na produção cultural o ser humano afirma sua condição ontológica de alguém que cria a própria morada espiritual em meio às circunstâncias concretas (ambientais, tecnológicas, econômicas, etc.) que lhe tocam. ${ }^{4}$

Assim, o ser humano é ser cultural, que se desdobra em ser jurídico, ser religioso, ser econômico, ser político, ou seja, em manifestações espirituais do indivíduo na relação com os demais e com a transcendência do ser. E o universo cultural do humano é um universo simbólico, suscetível a exame crítico racional de seus fundamentos e consequências, por meio da atividade filosófica.

Entretanto, na medida em que o ser humano cria a cultura ele depois também tende a ser normatizado por ela, regulamentado por ela. A cultura, desse modo, apresenta paradoxo, é criada e cria o indivíduo, porque mediada por ele, depois medeia regras e expectativas de comportamento que formatam a pessoa em determinado estilo de vida. A cultura, produzida

coisas temporais. No entanto, pela forma a obra penetra no universo simbólico, que lhe assegura uma perenidade ideal". (VAZ, 2002a, p. 90). O fato de a criação cultural específica ter existência precária e ameaçada deve-se, provavelmente, e, à razão de a criação cultural depender da memória e da preservação dos registros históricos

${ }^{4}$ A dimensão ontológica do ser humano já foi abordada por inúmeros filósofos ao longo da história, desde a concepção de alma baseada na teoria do mundo das formas em Platão até as mais recentes pesquisas fenomenológicas, passando por toda a contribuição medieval e moderna. Para aprofundamentos ver Mondin (1998). Entre autores contemporâneos cita-se Meneghetti (2010), que especifica a dimensão ontológica humana a partir do conceito de Em Si ôntico, enquanto princípio formal inteligente capaz de fazer autóctise histórica, intuindo nas circunstâncias históricas a solução ideal para cada contexto. 
pelo homem, influencia a criação jurídica, impacta na forma de o próprio homem se comportar.

E a cultura pode ser também um estímulo à criação de formas mais funcionais para o desenvolvimento individual e social, incluindo a dimensão jurídica. A cultura, quando intui as leis que regem a natureza humana, é capaz de fornecer caminhos pedagógicos para o aprimoramento comunitário. Esta cultura passa pela educação formal, pela filosofia, mas também pela estética, pela política, pelo direito. No próximo tópico aprofunda-se esta temática, trazendo para a discussão a ideia de paideia grega como ideal educacional voltado à formação integral do ser humano. Entende-se que esta abordagem pode oferecer contribuições valiosas para melhor compreensão e aplicação da política jurídica nos tempos contemporâneos.

\section{O CONCEITO DE PAIDEIA}

O conceito de Paideia é desenvolvido, sobretudo, a partir de Werner Jaeger em sua clássica obra 'Paideia: a formação do homem grego'. Nela o autor investiga o processo espiritual histórico de formação do homem grego, desde seus estágios primitivos na poesia homérica, a partir da ética heróica propagada pelas epopéias Ilíada e Odisséia, até o ápice com a filosofia clássica. Neste percurso a cada momento surgem novas circunstâncias que amplificam a formação do cidadão.

Para Jaeger toda sociedade, quando alcança certo grau de desenvolvimento, tende naturalmente à prática da educação, afinal ela é o "princípio por meio do qual a comunidade humana conserva e transmite a sua peculiaridade física e espiritual” (JAEGER, 2003, p. 3). Através da educação, mesmo com a mudança dos indivíduos no interior de uma comunidade, permanecem certos valores, princípios, modos sociais que constituem as relações e instituições naquela sociedade. O ser humano faz tudo isto por meio da razão e de sua vontade livre, perpetuando as forças sociais criadas por ele mesmo, como a família, a lei, as regras econômicas, políticas, a arte e os valores espirituais em geral.

Pela educação o ser humano conserva e transmite os conteúdos que determinam a cultura de sua civilização. E este processo deve conduzir para formas melhores de existência humana, a partir da descoberta progressiva dos mundos exterior e interior ao homem. A 
educação, desse modo, não é uma propriedade do indivíduo, mas da comunidade, e se expressa nas normas escritas e não escritas impressas nos seus membros e suas relações.

Para Jaeger a Grécia foi o momento da história das civilizações que melhor expressou a ideia de desenvolvimento cultural como busca de aprimoramento das experiências humanas individuais e sociais. A palavra que melhor expressaria esta preocupação, entre os gregos, é Paideia, que não pode ser facilmente traduzida, pois seriam necessárias várias palavras modernas juntas para expressar a totalidade de seu significado.

Não se pode evitar o emprego de expressões modernas como civilização, cultura, tradição, literatura ou educação; nenhuma delas, porém, coincide realmente com o que os gregos entendiam por paideia. Cada um daqueles termos se limita a exprimir um aspecto daquele conceito global, e, para abranger o campo total do conceito grego, teríamos de empregá-los todos de uma só vez. E, no entanto, a verdadeira essência da aplicação ao estudo e das atividades do estudioso baseia-se na unidade originária de todos aqueles aspectos - unidade vinculada na palavra grega -, e não na diversidade sublinhada e consumada pelas locuções modernas. (JAEGER, 2003, p. 1).

Apenas o uso conjugado de todos os termos permitiria o acesso a um significado mais completo do que os gregos entendiam por Paideia. Por trás da história do conceito de Paideia encontra-se a procura pelo desenvolvimento das potencialidades latentes do ser humano, enquanto indivíduo e comunidade.

A paideia não foi um conjunto de ideias abstratas, mas um percurso histórico que se utiliza de variadas manifestações, desde os tempos homéricos até os estágios clássicos dominados pelo aristotelismo. Entre estes vários séculos de desenvolvimento espiritual a paideia se revelaria na poesia época, na lírica, na política, nas tragédias e comédias teatrais, no direito, na filosofia, na ginástica, na medicina, na retórica, enfim, em tudo aquilo que de alguma forma expressa aspecto da vida comunitária. Neste sentido a paideia não surge como um modelo fixo ou uma linha de pensamento específica, mas como o empenho de muitas gerações no conhecimento e aprimoramento da realidade humana. Nem todos os autores e personalidades deste percurso concordam com o que é o ideal para o homem, mas todos procuram, de algum modo, aprimorar as capacidades humanas. Isto é verdadeiro seja para a lírica de Safo e sua preocupação com os sentimentos subjetivos seja para o ideal heróico dedicado ao trabalho em Hesíodo. 
Todo este empenho surgirá, aos olhos da história posterior, como o conjunto do produto cultural grego, ou melhor, do legado grego para a posterioridade. Quando se pensa na herança helênica logo vem à mente o nascimento da filosofia e seus inúmeros pensadores, as poesias homéricas, a arquitetura dórica, o militarismo espartano, as legislações de Sólon, o surgimento de instituições democráticas, etc. Enfim, há um elenco de criações espirituais que convencionalmente se apresenta como totalidade de produtos do espírito grego. Todo este produto é fruto da paideia, deste ideal pedagógico que conduz, de modo explícito ou implícito, a história cultural grega.

Neste sentido Jaeger explicita que paideia não pode ser entendida como cultura em uma acepção genérica, apenas como descrição antropológica dos costumes de determinado povo, ainda que esta visão tenha também sua validade e importância científica. Para Jaeger a paideia é cultura no sentido de carregar um ideal consciente de educação. Assim, a paideia enquanto cultura não é a descrição dos costumes atenienses, espartanos ou jônicos, mas o ideal pedagógico que move a cultura grega em busca do desenvolvimento das potencialidades individuais e sociais.

Portanto, a paideia helênica põe os fundamentos daquele modelo de educação que surgiria também na humanitas renascentista e na Bildung germânica, uma educação que tem o ser humano como centro e fim de todos os esforços culturais.

Porém, a inserção do ser humano nesta centralidade de esforços não significa que os gregos cultivassem uma visão atomística do indivíduo, como se este fosse desvinculado do ambiente. Pelo contrário, a ideia de autoconhecimento, ecoada em tantos pensadores gregos, reflete a intuição originária de que conhecer a si mesmo é encontrar as leis naturais que estruturam a própria condição existencial.

A vivacidade espontânea, a sutil mobilidade, a íntima liberdade [...] não têm as suas raízes no cultivo da subjetividade, como atualmente acontece; pertencem à sua natureza. E quando este povo atinge a consciência de si próprio descobre, pelo caminho do espírito, as leis e normas objetivas cujo conhecimento dá ao pensamento e à ação uma segurança antes desconhecida. (JAEGER, 2003, p. 10).

Quanto mais se aproxima do conhecimento de si, mais o indivíduo se descobre como parte da natureza, com leis precisas que governam seu corpo e seu pensamento. Isto se revelará no espírito grego por meio do fascínio que sentiam pelo estudo das leis naturais, 
retratadas esteticamente nas esculturas, na arquitetura, na ginástica, e em todo campo que se utilize de conhecimentos objetivos dos corpos.

Isto se revelará também na mais imponente invenção helênica: a filosofia. Também esta não surge como discurso relativista, mas como busca de compreensão das leis que regem os cosmos. Assim se dá desde Tales de Mileto e os pensadores pré-socráticos em geral. Também aqueles filósofos centralizados no estudo do homem citadino, como Sócrates, darão ênfase na busca por um logos que explique e justifique as condutas humanas. Para Sócrates, assim como para Platão, não é que os indivíduos pudessem agir livremente se quisessem realizar a própria satisfação existencial: a vida tem uma lógica e deve ser compreendida.

Os gregos portam adiante, então, a intuição de que o sujeito humano é capaz de criação cultural superior, em qualquer campo, da filosofia à medicina, passando pela política, pela economia, pelas artes em geral. Mas para ser capaz disso é preciso antes compreender radicalmente a lógica que preside a existência do próprio homem e do mundo em geral.

No que se refere ao problema da educação, a consciência clara dos princípios naturais da vida humana e das leis imanentes que regem as suas forças corporais e espirituais tinha de adquirir a mais alta importância. Colocar estes conhecimentos como força formativa a serviço da educação e formar por meio deles verdadeiros homens, como o oleiro modela a sua argila e o escultor as suas pedras, é uma ideia ousada e criadora que só podia amadurecer no espírito daquele povo artista e pensador. (JAEGER, 2003, p. 13).

E Jaeger complementa, salientando que o conhecimento destas leis imanentes é direcionado a um fim pedagógico, à criação do Homem vivo. A sensibilidade estética, a racionalidade filosófica, a eloquência política, a intuição jurídica, não são movimentos fins em si mesmos, mas dirigidos ao homem vivo e real que se movimenta na comunidade diariamente. (JAEGER, 2003, p. 13).

A paideia partia de uma forma ideal de ser humano, ou seja, não era uma pedagogia casuística, mas tentava adaptar os indivíduos históricos a um modelo ideal de formação. No entanto, esta forma ideal não pode ser confundida com um esquema abstrato e vazio, pois também a forma se adaptava conforme as circunstâncias e as novidades históricas trazidas pelos vários estágios percorridos pela cultura grega. ${ }^{5}$ Este ideal de ser humano atendia às

\footnotetext{
5 "Este ideal de Homem, segundo o qual se devia formar o indivíduo, não é um esquema vazio, independente do espaço e do tempo. É uma forma viva que se desenvolve no solo de um povo e persiste através das CONPEDI LAW REVIEW | EVENTO VIRTUAL | v. 6 | n. 1 | p. 236 - 251 | JAN - DEZ | 2020 
necessidades da vida comunitária. O indivíduo grego não pode ser pensado desvinculado da comunidade na qual está integrado.

A superior força do espírito grego depende do seu profundo enraizamento na vida comunitária, e os ideais que se manifestam nas suas obras surgiram do espírito criador de homens profundamente informados pela vida superindividual da comunidade. O Homem que se revela nas obras dos grandes gregos é o homem político. A educação grega não é uma soma de técnicas e organizações privadas, orientadas para a formação de uma individualidade perfeita e independente. (JAEGER, 2003, p.15).

A paideia não pode ser entendida desvinculada da política. O ser humano, para o grego, é sempre um ser político, membro ativo da sua comunidade. Não somente as leis e a retórica são atributos do mundo político, mas também a filosofia, a poesia e as artes em geral. O ser humano é político por natureza, sendo assim toda atividade espiritual humana é também atividade política, porque dirigida não apenas ao indivíduo em si mesmo, mas também à comunidade. O cidadão grego concebe a poesia visando formar o outro, intui as leis anatômicas na escultura para encantar e ensinar o outro, descobre novas formas governativas e legislativas para melhor administrar o outro. O outro está sempre no horizonte do cidadão grego, o outro como complemento a si na constituição comunitária.

Todo o futuro humanismo deve estar essencialmente orientado para o fato fundamental de toda a educação grega, a saber: que a humanidade, $\mathrm{o}$ 'ser do Homem' se encontra essencialmente vinculado às características do Homem como ser político. O fato de os homens mais importantes da Grécia se considerarem sempre a serviço da comunidade é índice da íntima conexão que com ela tem a vida espiritual criadora. [...] os grandes homens da Grécia não se manifestam como profetas de Deus, mas antes como mestres independentes do povo e formadores dos seus ideais. (JAEGER, 2003, p. 17).

O ideal de formação na paideia está sempre vinculada ao Estado, ao político. A paideia não existe somente para a contemplação, mas também para a ação. A paideia visa formar indivíduos capazes de orientarem e educarem os seus semelhantes. A paideia, portanto, representa a cultura como não apenas descrição de aspectos da vivência de determinado povo, mas de um ideal de cultivo, de formação do indivíduo para o social, como alguém capaz de interagir eticamente e funcionalmente com os demais. Esta formação é integral, e perpassa não apenas a filosofia, a poesia, a música, a estética em geral, mas também a retórica, a 
política e o direito. Não sem razão os gregos terão sempre em seu horizonte a dimensão metafísica do direito como expressão de leis que regem a comunidade da mesma forma em que há leis que regem a natureza. A paideia deve fornecer um ethos social superior, de tal forma que se adéque à natureza humana.

Ao longo da obra Jaeger apresenta as várias passagens da ideia de Paideia na história grega, iniciando pelas epopeias homéricas, mas atravessando a ética do trabalho em Hesíodo, a lírica, a pedagogia espartana, a formação política do cidadão, as contribuições de Sólon, dos grandes autores de teatro até o apogeu dos grandes sistemas filosóficos. A educação não era exatamente igual em todos os momentos, porque cada época e lugar confere atenção especial às suas necessidades, mas sempre foi feita sem perder de vista o objetivo de erguer concretamente um tipo ideal de ser humano.

Este ideal pode ser utilizado como referencial para a Política Jurídica, que é a área do direito que estuda como deveria ser o direito. O direito é também uma das técnicas pedagógicas de aprimoramento do indivíduo e da sociedade, e pode se aproveitar da riqueza intelectual deixada pela paideia grega para propor alternativas funcionais também às questões contemporâneas.

No próximo tópico aborda-se a questão da Política Jurídica, para que nas considerações finais sejam trazidas algumas reflexões relacionando política jurídica e paideia.

\section{PRODUÇÃO DO DIREITO E POLÍTICA JURÍdICA}

Política Jurídica, também denominada Política do Direito, consiste em uma disciplina que analisa o Direito sob as perspectivas de que deve ser e da maneira como deve ser contestando a descrição das regras jurídicas vigentes (Dogmática Jurídica) (MELO, 2000, p. 77).

Tal ciência tem o objetivo de ascender ao Direito almejado pela Sociedade, orientando-se, pelos parâmetros da Ética, Justiça, Legitimidade e Utilidade. Para atingir um Direito que respeite tais parâmetros, deve-se propor novas leis, adequar aquelas já vigentes e redefinir a própria ciência jurídica e seus núcleos. (CAVEDON, 2011, p. 65).

Sendo assim, compete para a Política do Direito a compreensão e assimilação das expectativas e carências da coletividade, incluindo no âmbito jurídico componentes de valor, CONPEDI LAW REVIEW | EVENTO VIRTUAL | v. 6 | n. 1 | p. 236 - 251 | JAN - DEZ | 2020 
os quais foram separados pela dogmática jurídica sob o argumento da segurança (MELO, 2000, p. 77).

Segundo a dogmática jurídica, toda norma positivada é válida, contanto que admitida pelas leis superiores, editada por sujeito que detém competência para tal e com firme cumprimento ao processo legislativo. No entanto, à Política do Direito, a validade de uma lei não deve ser auferida tão somente de sua apresentação formal, mas também deve ponderar a adequação ética de sua temática e afins (MELO, 1994, p. 87-88).

Nesse sentido, a Política Jurídica procura nas fontes formais e informais, os modelos jurídicos que a sociedade busca e que também possua adequação ética, em conformidade com a estética de convivência em sociedade, bem como com os princípios de liberdade e igualdade (MELO, 1994, p. 131).

A Política Jurídica precisa descobrir uma ciência jurídica que, através de sua legislação e normas em geral, possibilite um espaço onde seja admitido a estética do coexistir e relacionar-se, que possibilite aos indivíduos um nível autorrespeito mínimo e recognição mútua da dignidade de cada indivíduo. Isso deve ocorrer tanto no âmbito da relação entre indivíduos, como no âmbito da relação com o meio ambiente e o planeta (MELO, 1994, p. $63)$.

A Estética se apresenta como um meio de se obter o máximo de beleza do ser, da norma e do Direito. O Esteticismo é um termo utilizado para dar significado a uma conduta que se importe de forma superior com os princípios estéticos nos acontecimentos da vida. $\mathrm{O}$ indivíduo ético é aquele insubmisso à injustiça e ao incorreto, o ser estético não se conforma com o disforme ocasionado pela injustiça e pelo incorreto (MELO, 1994, p. 62). Nesse sentido, Osvaldo Ferreira de Melo pergunta o seguinte (1994, p. 62):

Se a grande função da arte é propiciar prazer espiritual, que prazer maior para o ser humano sensível do que o bem-conviver, a comunicação aberta, o sentir-se aceito na diversidade, e descobrir-se com as condições psicológicas e culturais de aceitar o pensar do outro?

Outrossim, a arte de viver consiste em uma contínua aplicação da estética na coexistência, uma criação de um espaço favorável ao aprimoramento da tolerância, diversidade de pensamentos, anuência dos valores dos demais. Nesse sentido, a democracia, em seu mais alto significado, quando transcende as simples estruturações políticas, obtém sua estética particular (MELO, 1994, p. 62). 
Para a Política do Direito, deve-se revisar as fontes formais da ciência jurídica, para beneficiar aquelas que de fato amparem um novo Direito, cobiçável, inovador, catártico, lógico e que atenda seu papel de atender às exigências da sociedade (MELO, 1994, p. 131).

Os propósitos da atuação político-jurídica propõem-se à quebra de padrões que recusam ou dificultam a inovação como um agir constante, garantindo, dessa forma, o enaltecimento do indivíduo e a dignidade de tratamento das pessoas entre si e com o meio ambiente (MELO, 1994, p. 132).

No livro Temas Atuais de Política do Direito, Melo ressalta alguns aspectos sobre a relevância do estudo da Política do Direito, inicialmente salientando a relação entre Direito e Política, aduzindo que é realizável e importante uma elaboração de uma teoria a respeito da harmonização entre Direito e Política, ambos compreendidos em categorias sob o ponto de vista ético-social e designadas as relativas concepções, tanto quanto possível, com a noção do justo e do legitimamente indispensável, isto é, do que é útil para a sociedade (MELO, 1998, p. 14).

Como consequência dessa mutualidade, o Direito carece da Política para constantemente desenvolver-se nas matrizes da legitimação, e a Política precisa do Direito para alcançar os anseios legítimos da sociedade, isto é, sugerir um conjunto de categorias, conceitos, princípios e normas aptos a garantir relações econômicas mais justas e a consecução de um espaço social ético e incentivador das condutas solidárias(MELO, 1998, p. 14).

Os pressupostos que apoiam os métodos de composição, interpretação e aplicabilidade do Direito zelam, principalmente, com a coerência e outros requisitos, descomprometidos com a essência ética que é inerente da ciência jurídica, sendo utilizada sem distinção para excessos autoritários e suporte a exigências da população. A Política Jurídica, por sua vez, projetada sobre parâmetros de sensatez e oportunidades, bem como baseada em critérios éticos, encontrar-se-á em serventia de um devir almejável e acessível, como sugestão inovadora às dificuldades que surgirem no percurso (MELO, 1998, p. 14).

A Política do Direito constitui-se prescritiva, e não descritiva. Ou seja, é compromissada com as urgências e aspirações da sociedade, e continuamente atraída pelas noções que lhe possibilitam ofertar a Ciência Jurídica, a Filosofia do Direito e a Sociologia 
Jurídica, na procura dos subsídios teóricos essenciais ao entendimento dos acontecimentos jurídicos e sociais (MELO, 1998, p. 14).

Deve-se destacar que a Política do Direito não consiste em apenas teoria, mas também se inclina à realização. Toda conduta retificadora e inovadora se voltará ao sistema legislativo em vigor, intervindo em sua constante adaptação e melhoria. (MELO, 1998, p. 14).

\section{CONSIDERAÇÕES FINAIS}

A partir daquilo que foi exposto pode-se demonstrar que a ideia de paideia, tal como apresentada por Jaeger, é capaz de oferecer subsídios importantes para a compreensão e aplicação da política jurídica, vez que esta busca determinar como o direito deveria ser, em contraposição à ciência jurídica, que estuda o direito que é.

Ora, para se buscar alternativas ao direito, apresentar caminhos que sejam inteligentes, úteis e funcionais ao indivíduo e sociedade, é fundamental compreender o que torna o ser humano mais desenvolvido enquanto indivíduo e sociedade.

Na política jurídica há implícita a dimensão pedagógica, de que o direito deve também encontrar meios para auxiliar as pessoas a se aprimorarem, e não apenas regulamentar as relações humanas. O operador do direito, seja ele o advogado, juiz, político, teórico, entre outras atividades, tem também uma função pedagógica a exercer, que é a de propor soluções inteligentes que representem ganho de vida para os membros da sociedade.

A política jurídica, quando imbuída do espírito da paideia, deixa de ser uma atividade casuística, que verifica caso a caso como reforçar a comunidade, e passa a procurar um tipo ideal de ser humano, tanto em perspectiva individual como social. De certa forma se descortina o horizonte metafísico.

A paideia grega não era apenas uma expressão cultural de certos valores e modelos de comportamentos, mas uma atividade abstrata de conceber um tipo ideal de ser humano, e por isto era capaz de modelar as atividades em geral (artes, filosofia, direito, política, etc.) para servirem a esta função de desenvolver o indivíduo. A paideia grega possuía uma noção de finalidade, de onde esperava chegar com sua proposta pedagógica. 
E esta formação estava sempre imersa no espírito comunitário. O indivíduo se desenvolvia no interior da própria sociedade. Por isto a paideia propõe sempre a ação, o envolvimento político, a interação que é capaz de dinamizar inteligentemente também as relações com os demais membros da sociedade.

Com a paideia a política jurídica pode recuperar esta busca pedagógica de estabelecer uma formação integral do ser humano. O direito e a política são espaços fundamentais da ação pedagógica. Mas para isto ser possível é essencial que os operadores do direito retomem uma formação clássica, humanista, que compreenda o ser humano em sua totalidade. A política jurídica não terá o êxito possível sem um entendimento mais profundo das leis que regem o ser humano enquanto corpo e atividade intelectual. Daí que uma formação integral, que perpasse a filosofia, a política, o direito, o teatro, a poesia, a música, a ginástica e tantas outras esferas da vida é fundamental para se estabelecer uma nova dimensão humanista para a política jurídica.

\section{REFERÊNCIAS BIBLIOGRÁFICAS}

CAVEDON, Fernanda de Salles; VIEIRA, Ricardo Stanziola. A Política Jurídica e o Direito Socioambiental:uma contribuição para a decidibilidade dos conflitos jurídicosambientais. Novos Estudos Jurídicos, Itajaí, edição especial, p. 60-78, 2011.

JAEGER, Werner. Paideia: a formação do homem grego. São Paulo: Martins Fontes, 2003.

MELO, Osvaldo Ferreira de. Dicionário de Política Jurídica. Florianópolis: OAB-SC, 2000.

MELO, Osvaldo Ferreira de. Fundamentos da Política Jurídica.Porto Alegre: Sergio Antonio Fabris; CPGD-UFSC, 1994.

MELO, Osvaldo Ferreira de. Temas Atuais de Política do Direito. Porto Alegre: Sergio Antonio Fabris, 1998.

MONDIN, Battista. Storia della Metafisica. Bologna: Studio Domenicano, 1998.

MOTTA, Moacyr Motta da. A ideia de Valor como fundamento do direito. In: CADEMARTORI, Daniela Mesquita Leutchuk de; GARCIA, Marcos Leite. Reflexões sobre Política e Direito: Homenagem aos Professores Osvaldo Ferreira de Melo e Cesar Luiz Pasold. Florianópolis: Conceito, 2008. 
MENEGHETTI, Antonio. Manual de Ontopsicologia. Recanto Maestro: Ontopsicologica Ed, 2010.

MONDIN, Battista. Storia della Metafisica. Bologna: Studio Domenicano, 1998.

SOARES, Josemar. Filosofia do Direito. Curitiba: IESDE, 2019.

VAZ, Henrique de Lima. Filosofia e Cultura: Escritos de Filosofia III. São Paulo: Loyola, 2002a. 